\title{
Identificação dos Serviços Ecossistêmicos prestados pelo manguezal da Ilha do Maranhão - MA, Brasil.
}

\author{
Identification of the Ecosystem Services provided by the mangrove of the Island of \\ Maranhão - MA, Brazil..

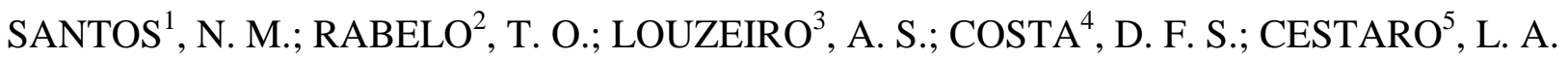 \\ nayaramarques3@hotmail.com;
}

\begin{abstract}
Resumo
Os manguezais são importantes ecossistemas que produzem uma gama de serviços ecossistêmicos (SE). Na Ilha do Maranhão esses ambientes são bastante expressivos, porém devido ao crescimento urbano, essas áreas têm sido intensamente degradadas. O objetivo desta pesquisa foi identificar e classificar os SE de provisão, regulação/manutenção e culturais prestados pelos manguezais da Ilha do Maranhão. Para isto foi utilizado a Classificação Internacional Comum dos Serviços Ecosssistêmicos (CICES) como base para identificação destes SE, assim como levantamento e análise de material bibliográfico e cartográfico. Os serviços identificados variaram desde a utilização da flora do mangue como fonte de energia, contribuições físico-quimicas para manutenção da qualidade da água, até do manguezal como inspiração para composição de músicas e poemas. Contudo, Ainda são incipientes os trabalhos que abordam os SE na Ilha do Maranhão. Porém muitas pesquisas já fazem menção as funções destes ecossistemas e consequentemente aos serviços que podem ser prestados.
\end{abstract}

Palavras-chave: Serviços Ecossistêmicos, Manguezal e Ilha do Maranhão.

\begin{abstract}
Mangroves are important ecosystems that produce a range of ecosystem services (SE). In Maranhão Island these environments are quite significant, but due to urban growth, these areas have been heavily degraded. The objective of this research was to identify and classify the provision of SE, regulation / maintenance and cultural provided by mangroves of Maranhao Island. For this we used the International Classification of Common Ecosssistêmicos Services (Cices) as the basis for identification of these SE, as well as survey and analysis of bibliographical and cartographic material. The services identified ranged from the use of the mangrove flora as an energy source, physical-chemical contributions to water quality maintenance, to the mangroves as inspiration for composing music and poems. However, they are still incipient works that address the SE in Maranhão Island. But many studies already make mention of the functions of these ecosystems and consequently the services that can be provided.
\end{abstract}

Keywords Ecossystem Services, Mangrove and Island of Maranhão.

\section{INTRODUÇÃO}

Os processos ecológicos dos ecossistemas são responsáveis pelo funcionamento dos sistemas ambientais e pela prestação de serviços para manutenção da qualidade de vida, estes são denominados de Serviços Ecossistêmicos (SE). Os SE são bens tangíveis e intangíveis produzidos pelos ecossistemas, utilizados pela sociedade em busca do bem estar humano, a exemplo da

\footnotetext{
${ }^{I}$ Nayara Marques Santos, Doutoranda em Geografia, Universidade Federal do Rio Grande do Norte, Natal-RN, Brasil.

${ }^{2}$ Thiara Oliveira Rabelo, Doutoranda em Geografia, Universidade Federal do Rio Grande do Norte, Natal-RN, Brasil.

${ }^{3}$ Andreza dos Santos Louzeiro, Doutoranda em Geografia, Universidade Federal do Rio Grande do Norte, Natal-RN, Brasil.

${ }^{4}$ Diógenes Félix da Silva Costa, Departamento de Geografia, Universidade Federal do Rio Grande do Norte, Natal-RN, Brasil.

${ }^{5}$ Luiz Antonio Cestaro, Departamento de Geografia, Universidade Federal do Rio Grande do Norte, Natal-RN, Brasil.
} 
provisão de alimentos, água potável, atividades de lazer, proteção a desastres naturais, regulação climática, entre outros (CONSTANZA et al., 1997).

A identificação dos serviços prestados pelos ecossistemas é importante, pois permite quantificar a relevância que estes ambientes têm para a sociedade, tratar os impactos causados por ações antrópicas ou naturais de forma especifica, valorar perdas e ganhos de acordo com os usos atribuídos a estes e conhecer os valores intangíveis que os ecossistemas podem assumir.

As intensas intervenções provocadas pela ação humana nos ecossistemas têm provocado alterações nas funcionalidades e comprometido a prestação dos SE, e o manguezal é um dos mais afetados pelas atividades humanas (BARBIER et al., 2011). Caracterizado como uma das áreas úmidas de elevada importância ecológica (SCOTT; JONES, 1995; JUNK et al., 2014), o manguezal, é um ambiente onde ocorrem intensos processos biológicos e geoquímicos, sendo fonte de renda e subsistência para muitas comunidades, assim como fornece condições para o desenvolvimento de outras atividades.

Nesta perspectiva, destaca-se o manguezal da Ilha do Maranhão, localizada na região do Golfão Maranhense, na porção norte do Estado Maranhão, região nordeste do Brasil. Formada pelos municípios de São Luís, São José de Ribamar, Paço do Lumiar e Raposa, com área total de aproximadamente 1.412,264 $\mathrm{Km}^{2}$ (IBGE, 2010). O ecossistema ocorre de forma bem expressiva na ilha, sendo alvo de intensa pressão antrópica devido ao crescimento urbano, desencadeando uma série de impactos negativos sobre este ambiente (MOREIRA; BRITO; FARIAS FILHO, 2015).

A presente proposta teve como objetivo identificar os serviços ecossistêmico de provisão, regulação/manutenção e culturais prestados pelo de manguezal da Ilha do Maranhão, no intuito de conhecer a diversidade de bens ofertados por este ecossistema para sociedade local e fornecer subsídios para a elaboração de propostas de gestão mais sustentáveis para estas áreas, devido a representatividade deste ecossistema na Ilha.

\section{METODOLOGIA}

O presente artigo teve como principal procedimento metodológico a realização de uma levantamento e análise bibliográfica de trabalhos que abordam sobre o ecossistema manguezal na Ilha do Maranhão. Como elementos métricos desta revisão, buscou-se realizar a obtenção de informações em livros, periódicos indexados e no acervo da Biblioteca Setorial da Universidade Federal do Maranhão e do Laboratório de Manguezais (LAMA - UFMA), associando-se as palavras chave como: mangue, manguezal, São Luís, Ilha do Maranhão, Raposa, poemas, música e outras. 
Após esta etapa, como suporte teórico para identificação e classificação a Common International Classification of Ecosystem Services - CICES (HAINES-YOUNG; POTSCHIN, 2013), a Classificação Comum Internacional dos Serviços Ecossistêmicos e o trabalho de Sousa et al. (2016) sobre classificação e mapeamento de SE prestados por uma região costeira de Portugal.

A CICES segue uma estrutura hierárquica como forma de permitir que seus usuários selecionem o nível mais adequado para sua aplicação. No mais alto nível (chamado 'seções') existem três grandes categorias, aninhadas numa série de "divisões", "grupos" e "classes". Considera as saídas dos ecossistemas dependentes de processos de vida, no entanto, não inclui matérias abióticos e energia abiótica na sua matriz potencial de trabalho, mas como uma matriz de acompanhamento (SOUSA et al., 2016). Os serviços são classificados em três grandes áreas: os serviços de provisão, regulação/manutenção e culturais, e subdivididos em classes e grupos.

$\mathrm{Na}$ identificação e classificação dos serviços ecossistêmicos prestados pelo ecossistema manguezal na Ilha do Maranhão elaborou-se uma tabela com a síntese dos SE fornecidos pelos manguezais na área de estudo, tendo como suporte estudos e pesquisas direcionados aos manguezais da Ilha assim como, a partir de observações em campo.

Essa tabela foi adaptada de acordo com a realidade da área de estudo desta pesquisa. Ressalta-se que nem todos os grupos e classes estão contempladas na tabela, pois não foram encontrados dados que pudessem validar a prestação de determinados serviços. Foram levantados 82 trabalhos disponíveis em forma de artigos, teses, dissertações, monografias, capítulos de livro, sites e blogs de autores que tratam direta ou indiretamente da área de manguezal da Ilha do Maranhão. Com base nesse referencial foi possível identificar os serviços relacionados à provisão, regulação/manutenção e cultura localizados na área de estudo (Figura 01).

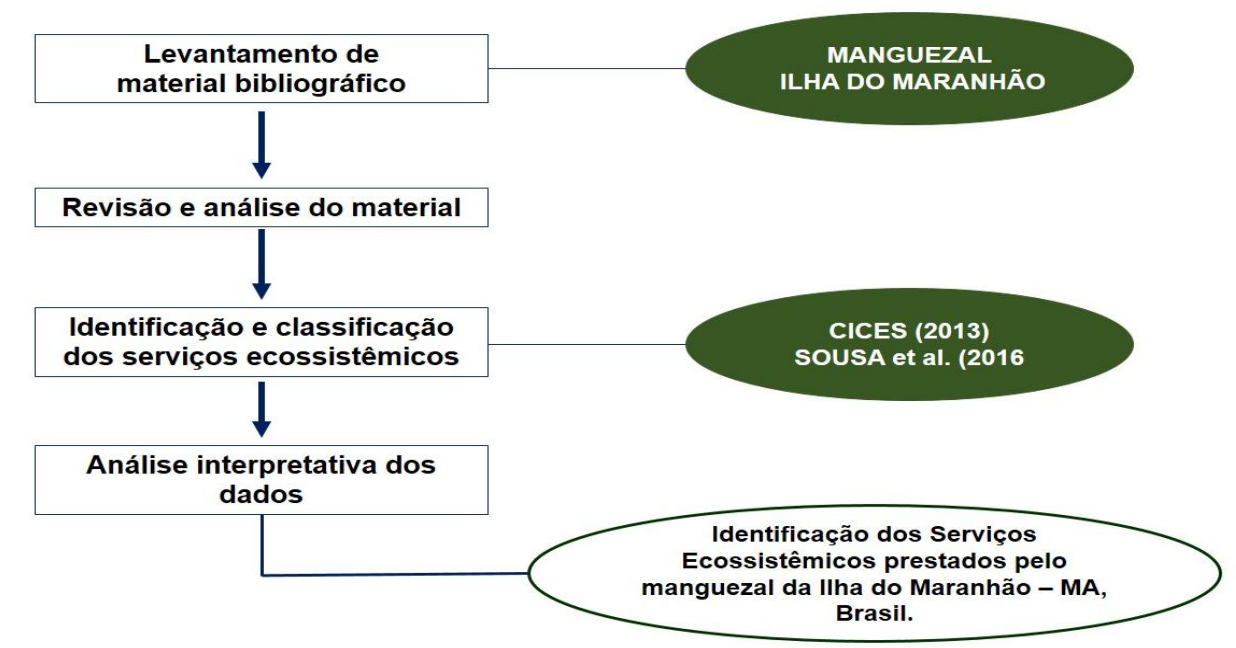

Figura 01: Fluxograma síntese das etapas da pesquisa. Fonte: Elaborado pelos autores. 
2.1 Localização da área de estudo: O ecossistema manguezal na Ilha do Maranhão

$\mathrm{Na}$ Ilha do Maranhão, o ecossistema manguezal se apresenta de forma bem expressiva. Segundo Souza e Feitosa (2009), a área de estudo caracteriza-se pela fragilidade das estruturas geológicas, constituídas essencialmente de coberturas do Cenozóico, o que facilita a alteração da paisagem por sua exposição aos agentes modeladores do relevo de origem climática (ventos alísios) e oceanográfica (marés), e pela intensa atividade eólica, marinha e fluvio-marinha e aporte de sedimentos continentais carreados pelos rios que fortalecem o aparecimento de ambientes como os manguezais.

Essa zona costeira está classificada como uma costa sob regime de macromarés, com variações de $-0,2$ a +8,0 metros e amplitudes até 4,0 metros. Em alguns locais na baía de São Marcos as marés podem alcançar mais de 9 metros. As correntes de marés, superiores a 3m/s no Golfão Maranhense podem provocar a erosão das margens dos estuários e a queda das árvores dos manguezais (MOCHEL, 2011; SCHAEFFER-NOVELLI; CINTRON, 1990).

Segundo os dados do ano de 2009 do Instituto Maranhense de Pesquisas Socioeconômicas e Cartográficas - IMESC, a Ilha do Maranhão, possui uma área de manguezais correspondentes as $105 \mathrm{~km}^{2}$ (Figura 02), que se constituem como um dos ecossistemas mais degradados da Ilha, devido principalmente a ação humana nestas áreas.

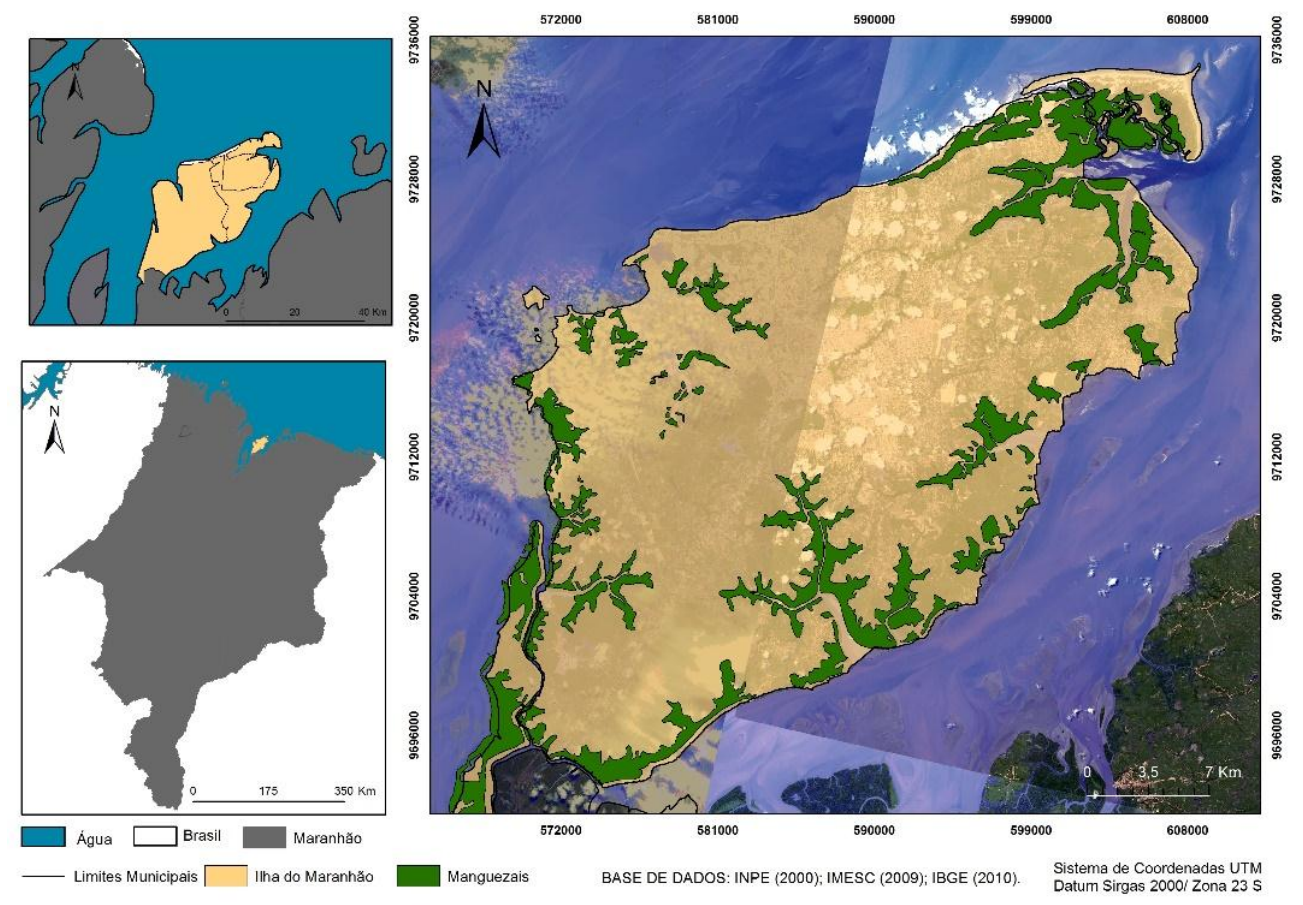

Figura 02: Espacialização do ecossistema manguezal na Ilha do Maranhão. Fonte: Elaborado pelos Autores. 
O manguezal da Ilha de São Luís é composto pelas espécies de Rhizophora mangle L., Avicennia germinans L., A. schaueriana Stapf \& Leechm e Laguncularia racemosa (L.) C.F. Gaert, embora seja comum a ocorrência de ii e Rhizophora harrisonii e outras espécies associadas como Conocarpus erectus, Achrostichum aureum, entre outros (REBELO-MOCHEL, 1997). De acordo com Mochel (2011) as árvores adultas podem apresentar alturas inferiores a 1 metro nos ambientes estressados pela salinidade e superar 35 metros nas áreas de maior aporte de águas doces, argilas e marés de grande altura, sendo mais comuns variações entre 25 e $35 \mathrm{~m}$.

É importante destacar que além do pescado, o caranguejo-uçá é um importante recurso socioeconômico na Ilha. Segundo Mochel et al. (2001), outras espécies de importância socioeconômica são os siris-azuis, principalmente o Callinectes bocourti e o marisco, Lucina pectinata.

\section{RESULTADOS E DISCUSSÕES}

\section{SERVIÇOS ECOSSISTÊMICOS PRESTADOS PELO MANGUEZAL DA ILHA DO MARANHÂO}

\subsection{Serviços de Provisão}

Estes serviços, segundo Haines-Young e Potschin (2010) incluem todos as saídas materiais e energéticas dos ecossistemas, ou seja, os bens tangíveis que podem ser trocadas ou negociadas, consumidos ou usados diretamente na fabricação de outros produtos. A seguir serão listados os SE de provisão encontrados nos manguezais da Ilha do MA (Tabela 01).

Tabela 01: Classificação dos Serviços Ecossistêmicos de provisão prestados pelo manguezal da Ilha do Maranhão. Fonte: Elaborado pelos autores

\begin{tabular}{|c|c|c|c|}
\hline \multicolumn{4}{|c|}{ SERVIÇOS ECOSSISTÊMICOS DE PROVISÃO } \\
\hline DIVISÃO & GRUPO & CLASSE & AUTORES \\
\hline \multirow{4}{*}{ NUTRIÇÃO } & \multirow{4}{*}{ Biomassa } & $\begin{array}{l}\text { Animais criados e } \\
\text { suas saídas }\end{array}$ & $\begin{array}{c}\text { Rebelo-Mochel } \\
\text { (1997); Mochel et al. } \\
\text { (2001); Monteles et } \\
\text { al. (2009); Paixão et } \\
\text { al. (2007) }\end{array}$ \\
\hline & & $\begin{array}{l}\text { Plantas silvestres, } \\
\text { algas e suas saídas }\end{array}$ & $\begin{array}{c}\text { Mochel (1997); } \\
\text { Mochel et al. (2001) }\end{array}$ \\
\hline & & $\begin{array}{c}\text { Animais selvagens e } \\
\text { suas saídas }\end{array}$ & Mochel (1997) \\
\hline & & $\begin{array}{l}\text { Animais de } \\
\text { aquicultura in-situ }\end{array}$ & Brasil (2003) \\
\hline MATERIAIS & Biomassa & $\begin{array}{c}\text { Fibras e outros } \\
\text { materiais de plantas, } \\
\text { algas e animais para } \\
\text { uso direto ou }\end{array}$ & $\begin{array}{l}\text { Rebelo-Mochel } \\
\text { (1997); Mochel } \\
\text { (2001; 2011); } \\
\text { Moucherek Filho et }\end{array}$ \\
\hline
\end{tabular}




\begin{tabular}{|c|c|c|c|}
\hline & & transformação & al. (2003). \\
\hline & & $\begin{array}{l}\text { Materiais genéticos } \\
\text { da biota }\end{array}$ & $\begin{array}{l}\text { Moraes et al. (2010); } \\
\text { Mochel et al. (2001) }\end{array}$ \\
\hline ENERGIA & $\begin{array}{l}\text { Fontes de energia a } \\
\text { partir de biomassa }\end{array}$ & $\begin{array}{c}\text { Recurso a base de } \\
\text { plantas }\end{array}$ & Mochel (1997; 2011) \\
\hline
\end{tabular}

No que se refere a classe de serviços relacionadas a animais e suas saídas, no ecossistema de manguezal da Ilha é comum a utilização da fauna característica destes ambientes para consumo pelas populações que se encontram na área de influência direta do mangue, assim como para comercialização e consumo em outros pontos da cidade que distam dos pontos de coleta.

As espécies mais comuns encontradas e utilizadas para consumo são os camarões, moluscos, crustáceos, ostras, peixes, a exemplo do: caranguejo - Ucides cordatus (Ocypodidae), Uca thayeri (Ocypodidae), sururu - Mytella falcata (Mytillidae) e M. guyanensis (Mytillidae), mariscos - Lucina pectinata (Lucinidae), siri - Callinectes bocourti (Portunidae), camarão Penaeus schmitti (Penaeidae), sarnambi - Anomalocardia brasiliana (Veneridae), tarioba Iphigenia brasiliensis (Donacidae)(MOCHEL, 1997; MOCHEL, 2011; PAIXÃO et al., 2007; MONTELES et al., 2009;,).

Com relação a presença das plantas silvestres, algas e suas saídas, os manguezais produzem importantes fontes nutricionais para dinâmica da cadeia alimentar dentro deste ecossistema, onde raízes, troncos, folhas, algas e outros servem de alimento para outras espécies, como é o caso de caranguejos e insetos que consomem as folhas da serapilheira.

Mochel et al. (2001) destacam que no relatório do Grupo de Estudo sobre o U. cordatus realizado em 1994, apontaram como as folhas de $R$. mangle como uma importante fonte alimentar para este caranguejo e no manguezal localizado no sudoeste da Ilha, a maioria dos caranguejos coletados foram encontrados sob as arvores de R. mangle. Estudos desenvolvidos por RebeloMochel (1997) e Mochel et al. (2001) identificam essa variedade de plantas e algas presentes nos manguezais da Ilha que compõe parte a cadeia alimentar deste sistema.

Na classe de animais selvagens, destaque para a produção de mel nos manguezais da Ilha de Tauá - Mirim, localizada na porção sudoeste da área de estudo. Rebelo-Mochel (1997) apud Mochel (1993) afirma, que a extração do mel é realizada de forma predatória, onde as árvores do mangue (Avicennia) são cortadas para ter acesso até as colmeias. As abelhas encontradas nos mangues de São Luís, são do gênero Melipona e Apis, de acordo com Rebelo-Mochel (1997). 
Para aquicultura de animais, há informações referentes a projetos de extensão voltados para cultivos de ostra e sururu no município da Raposa e criação de sururu no povoado de Tibumba em Paço do Lumiar (BRASIL, 2003).

Na subdivisão de materiais, referente ao grupo da biomassa, a produção de fibras e outros materiais de plantas, algas e animais para uso direto ou transformação, é caracterizado no contexto da Ilha, como a produção de madeira das árvores de mangue convertidas em lenha e carvão, e para outros usos domésticos, construção de pontes e embarcações.

Arvores de Rizophora e Avicennia também são cortadas para extração de tanino, um polifenol presente na casca do mangue, utilizado para diversos fins, como tingimento de redes e velas de embarcações, para curtume, fins farmacêuticos, entre outros. (REBELO-MOCHEL, 1997; MOCHEL et al., 2001; MOCHEL, 2011).

Moucherek Filho et al. (2003) faz uma análise organoléptica e bromatológica para fins nutricionais do camarão, caranguejo e sururu consumidos em São Luís, onde ele indica as carnes mais adequadas para consumo de acordo com o valor calórico de cada, concluindo que o camarão é o mais indicado para compor uma dieta alimentar. Com relação aos materiais genéticos, pode-se enfatizar a utilização dos propágulos produzidos pelos mangues, para ações de recuperação das áreas degradadas no ecossistema, assim como o cultivo de espécies (MOCHEL, 2001; MORAES et al., 2010).

No grupo das fontes de energia a base de biomassa, na classe recursos à base de plantas, destaca-se Rebelo-Mochel (1997), quando afirma que a lenha e o carvão vegetal produzidos a partir das árvores do mangue são utilizados como fonte de energia em padarias, olarias e no uso doméstico. Já para a classe recursos energéticos a base de animais, não há referências sobre a fauna de manguezais da Ilha sendo utilizada como fonte de energia, nem conhecimento local suficiente.

\subsection{Serviços de Regulação e Manutenção}

De Groot et al. (2002) e Haines - Yong e Potschin (2010) se referem a estes serviços como a capacidade dos ecossistemas naturais e semi-naturais regular os sistemas e processos ecológicos essenciais para dar suporte a vida como ciclos biogeoquímicos e outros processos da biosfera. Os autores ainda enfatizam quem estas funções de regulação fornecem muitos serviços que tem benefícios diretos e indiretos para os seres humanos, tais como: ar limpo, água, solo e serviços de controle biológico. 
Tabela 02: Classificação dos Serviços Ecossistêmicos de regulação/manutenção prestados pelo manguezal da Ilha do Maranhão. Fonte: Elaborado pelos autores

\begin{tabular}{|c|c|c|c|}
\hline \multicolumn{4}{|c|}{ 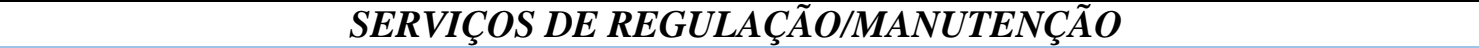 } \\
\hline DIVISÃO & GRUPO & CLASSES & AUTORES \\
\hline \multirow[t]{3}{*}{$\begin{array}{l}\text { Mediação de } \\
\text { resíduos, } \\
\text { produtos } \\
\text { tóxicos e } \\
\text { outras } \\
\text { perturbações }\end{array}$} & $\begin{array}{l}\text { Mediação de } \\
\text { biota }\end{array}$ & $\begin{array}{c}\text { Filtração/sequestro/acumulação de } \\
\text { microorganismos, algas, plantas e } \\
\text { animais. }\end{array}$ & $\begin{array}{c}\text { Mochel et al. } \\
\text { (2001);/ Nogueira } \\
\text { e Correia (2001); } \\
\text { Paixão et al. } \\
\text { (2007); Correia e } \\
\text { Brandão (1974); } \\
\text { Silva e Almeida } \\
\text { (2002); Azevedo e } \\
\text { Cutrim (1999); } \\
\text { Cutrim et al. } \\
\text { (2008) }\end{array}$ \\
\hline & \multirow[b]{2}{*}{$\begin{array}{l}\text { Mediação } \\
\text { pelos } \\
\text { ecossistemas }\end{array}$} & $\begin{array}{l}\text { Filtração/Sequestro/armazenamento/ } \\
\text { Acumulação por ecossistemas }\end{array}$ & Medeiros (2005) \\
\hline & & $\begin{array}{c}\text { Diluição pela atmosfera, água doce e } \\
\text { marinha. }\end{array}$ & $\begin{array}{l}\text { Macedo e Rocha } \\
\text { (1984) }\end{array}$ \\
\hline \multirow{3}{*}{$\begin{array}{l}\text { Mediação dos } \\
\quad \text { fluxos }\end{array}$} & \multirow{2}{*}{$\begin{array}{l}\text { Fluxos de } \\
\text { massa }\end{array}$} & $\begin{array}{c}\text { Estabilização e controle de taxas de } \\
\text { erosão }\end{array}$ & $\begin{array}{c}\text { Oliveira e Mochel } \\
\text { (1999); Novaes et } \\
\text { al. (2007) }\end{array}$ \\
\hline & & $\begin{array}{l}\text { Tampão e atenuação dos fluxos de } \\
\text { massa }\end{array}$ & Bezerra (2008) \\
\hline & $\begin{array}{l}\text { Fluxos } \\
\text { gasosos/ar }\end{array}$ & Proteção contra inundações & Bezerra (2014) \\
\hline \multirow{3}{*}{$\begin{array}{c}\text { Manutenção } \\
\text { química } \\
\text { condições } \\
\text { biológicas } e \\
\text { físicas }\end{array}$} & $\begin{array}{l}\text { Manutenção } \\
\text { do ciclo de } \\
\text { vida habitat e } \\
\text { proteção } \\
\text { conjunta de } \\
\text { genes. }\end{array}$ & $\begin{array}{l}\text { Manter populações e habitats de } \\
\text { berçário }\end{array}$ & $\begin{array}{l}\text { Carvalho Neta e } \\
\text { Castro, 2008; } \\
\text { Paixão et al. } \\
\text { (2007); Oliveira e } \\
\text { Mochel (1999); } \\
\text { Cruz, Martinéz e } \\
\text { Fernandes (2007) }\end{array}$ \\
\hline & $\begin{array}{l}\text { Formação do } \\
\text { solo }\end{array}$ & $\begin{array}{l}\text { Processo de intemperismos } \\
\text { Processo de decomposição e fixação }\end{array}$ & $\begin{array}{l}\text { Oliveira e Mochel } \\
\text { (1999) }\end{array}$ \\
\hline & $\begin{array}{l}\text { Condições da } \\
\text { água }\end{array}$ & Condições Químicas da água doce & $\begin{array}{l}\text { Mochel et al. } \\
\text { (2001) Carvalho } \\
\text { Neta e Castro } \\
\text { (2008); Martins } \\
\text { (2008); Nunes } \\
\text { (2013); Silva et al; } \\
\text { (2014) }\end{array}$ \\
\hline
\end{tabular}

Os serviços da divisão "Mediação de resíduos, produtos tóxicos e outras perturbações" foram divididos em duas classes: Mediação de biotas e Mediação pelos ecossistemas. Para a 
primeira classe consideramos processos de Filtração/sequestro/acumulação de microorganismos, algas, plantas e animais e para a segunda classe estes processos foram enfatizados a nível de ecossistema.

No que diz respeito aos serviços prestados por este grupo enfatizamos as pesquisas de Mochel et al. (2001) que enfatizam a importância das espécies de Rhizophora, Avicennia e Laguncularia, para os manguezais da Ilha, visto que produzem troncos e raízes (escoras e pneumatóforos), localizadas nas zonas entre marés; onde seus ramos folhosos oferecem proteção aos troncos e raízes do excessivo calor e luz do sol, tornando-os um substrato ideal para o crescimento de algas.

Mochel et al. (2001), Nogueira e Correia (2001) e outros autores enfatizam os poucos estudos referentes a algas na Ilha do Maranhão, tendo estes autores a preocupação de começar identificar estes organismos fotossintetizantes na área.

Quanto a regulação e conservação faunística do manguezal, que está intimamente ligada também a prestação dos serviços de provisão, enfatizamos os estudos de Paixão et al (2007), que deixa claro em suas pesquisas a influência que os sedimentos do substrato do mangue e a pluviosidade tem sobre a abundância e ocorrência de caranguejos chama-marés do gênero Uca (crustacea, ocypodidae) no manguezal do Araçagy, na Ilha do Maranhão.

Autores como Medeiros (2005) enfatiza a mediação destes serviços por ecossistema, fazendo menção ao valor ecológico dos manguezais para a Ilha e dando ênfase principalmente a regulação biológica da área, através das áreas de mangue. Macedo e Rocha (1984) também enfatiza estes serviços por ecossistemas como importantes para controle de poluição causado por esgotos nos estuários da Ilha do Maranhão.

Estes autores afirmam que a demanda bioquímica de oxigênio, da demanda bentônica de oxigênio, das marés de intrusão marinha, podem contribuir também para o planejamento de sistemas de esgotos que seja tecnicamente viáveis e ecologicamente e sanitariamente aceitáveis, antes de planejar os convencionais sistemas de disposição no mar.

Os serviços de regulação referente a divisão de "Mediação de fluxos" foram divididos em duas classes: Fluxos de massa e Fluxos gasoso/ar. Para a primeira classe, consideramos os processos de estabilização e controle de taxas de erosão e os processos de tampão e atenuação dos fluxos de massa; e para segunda classe capacidade de suporte para proteção contra inundações.

No contexto dos serviços prestados por este grupo, destacamos as pesquisas de Oliveira e Mochel (1999), que apontam áreas no sudoeste da Ilha como mais erodidas e assoreadas a partir da 
retirada da vegetação de mangue. Porém nesta região da ilha outros problemas ambientais além do desmatamento podem ser pontuados como casos de derramamentos de óleo advindos de atividades portuárias na Baía de São Marcos e despejos de matadouros.

Com base nas especificidades desde cenário, Oliveira e Mochel (1999) enfatizam que as áreas erodidas, assoreadas e desmatadas apresentam maior diversidade de endofauna (poliquetos, bivalves e crustáceos) do que as áreas impactadas por óleo e por despejo de matadouros.

A importância da conservação dos manguezais na Ilha por conta de processos de fluxos líquidos é essencial. Em muitas áreas que antes eram cobertas por vegetação de mangue, em períodos chuvosos são cenários de inundações. Bezerra (2008) enfatiza que o ecossistema manguezal, encontra-se mais suscetível ao processo de expansão do perímetro urbano, dando como exemplo a áreas da Ilha do Maranhão que estão sujeitas a inundações de maré e que apresentam sedimentos inconsolidados, como é o caso a bacia do Rio Anil.

No que se refere a resistência potencial dos manguezais a elevação do nível do mar na Ilha, o trabalho de Bezerra (2014) destaca-se como pioneiro. Este pesquisador levou em consideração dados sobre regime de ventos, ondas, solos e a vegetação de mangue, chegando a conclusões que evidenciam a capacidade de resistência do manguezal da Ilha a elevação média do nível do mar.

Quanto aos serviços prestados pela divisão de "Manutenção química condições biológicas e físicas" estes foram divididos em 4 classes: Manutenção do ciclo de vida habitat e proteção conjunta de genes; Formação do solo e Condições da água.

Carvalho Neta e Castro (2008) foram um dos autores que enfatizaram a importância dos manguezais para manter populações e berçários de habitats, mostrando por exemplo o serviço prestado pelo manguezal na Ilha de Caranguejos, territorialmente pertencente a Ilha do Maranhão, e sua contribuição para a diversidade de peixes estuarinos.

Assim como os demais autores citados neste grupo na tabela 02 que enfatizaram a importância dos manguezais para manutenção das condições biológicas de vida, Carvalho Neta e Castro (2008) afirmaram em seu estudo de caso que a composição da ictiofauna foi caracterizada por uma mudança gradual na dominância das principais espécies nos igarapés da área e que a grande participação na amostragem por juvenis de todas as espécies sugere que a zona estuarina é utilizada principalmente para alimentação e crescimento.

Embora também deem ênfase a estes serviços prestados pelo manguezal, Oliveira e Mochel (1999) também apontam a importância dos manguezais no que se refere a formação dos 
solos, posto que as áreas conservadas com vegetação de mangue sejam mais propicias para a manutenção do e conservação do substrato do mangue, evitando a erosão e o assoreamento.

Quanto as condições da água, existem alguns estudos direcionados como o de Nunes (2013) se dirige a estudar o fracionamento de fósforo nos sedimentos dos rios Bacanga e Anil, inseridos no ecossistema manguezal da Ilha, chegando a conclusões de que "Os sedimentos têm capacidade mais expressiva de adsorção de fosfato dentro dos parâmetros de isotermas, que podem atuar como um fator de mitigação contra a contribuição significativa de fósforo através de esgoto".

Mochel et al. (2001) analisaram nutrientes e algumas variáveis físico-químicas do Igarapé Arapopaí, situado da área de estudo. Foram avaliadas as condições nitrato, nitrito, amônia, silicato, fósforo inorgânico e fósforo total dissolvido.

Em geral as varáveis físicas e químicas e nutrientes não variaram entre as estações amostradas (período chuvoso e de estiagem), mas as águas investigadas mostraram altas concentrações de fósforo sugerindo mais contribuições naturais, do ecossistema manguezal, para as condições da água, do que antrópicas, posto que é uma área medianamente impactadas por atividades humanas.

\subsection{Serviços Culturais}

Os serviços culturais prestados pelos manguezais são pouco estudados, a maioria dos trabalhos estão ligados aos bens de provisão e regulação devido ao seu elevado reconhecimento socioeconômico. Considerando as classes propostas por Haines-Young e Potschin (2010), os serviços culturais estão ligados a bens intangíveis, informacionais, educativos, saberes tradicionais e outros.

Tabela 03: Classificação dos Serviços Ecossistêmicos culturais prestados pelo manguezal da Ilha do Maranhão. Fonte: Elaborado pelos autores

\section{SERVIÇOS CULTURAIS}

\begin{tabular}{|c|c|c|c|}
\hline DIVISÃO & GRUPO & CLASSE & AUTORES \\
\hline $\begin{array}{c}\text { Interações físicas e } \\
\text { intelectuais com a } \\
\text { biota, ecossistemas } \\
\text { e terra-marinha } \\
\text { [definições } \\
\text { ambientais] }\end{array}$ & $\begin{array}{c}\text { Interações físicas } \\
\text { e experiências }\end{array}$ & $\begin{array}{l}\text { Uso experimental de } \\
\text { plantas, animais e } \\
\text { terrestres/marinhas em } \\
\text { diferentes contextos } \\
\text { ambientais }\end{array}$ & Ferretti (2009) \\
\hline \multirow{2}{*}{$\begin{array}{c}\text { Interações } \\
\text { espirituais, } \\
\text { simbólicas e outras }\end{array}$} & \multirow{2}{*}{$\begin{array}{l}\text { Interações } \\
\text { intelectuais e de } \\
\text { representação }\end{array}$} & Científico & Diversos \\
\hline & & Educacional & $\begin{array}{l}\text { Projeto CERMANGUE } \\
\text { - UFMA (profa. Flávia }\end{array}$ \\
\hline
\end{tabular}




\begin{tabular}{|c|c|c|}
\hline $\begin{array}{c}\text { com a biota, } \\
\text { ecossistemas e } \\
\text { terra/marinhas } \\
\text { [definições } \\
\text { ambientais] }\end{array}$ & Herança Cultural & $\begin{array}{c}\text { Mochel - coordenadora) } \\
\text { Poesias (Zenilton de } \\
\text { Jesus Gayoso Miranda e } \\
\text { José Francisco das } \\
\text { Chagas) }\end{array}$ \\
& & $\begin{array}{c}\text { Toponímia - Matos } \\
(2014)\end{array}$ \\
\hline & Entretenimento & $\begin{array}{c}\text { Santos, Oliveira e } \\
\text { Pereira (2011) }\end{array}$ \\
\hline & Sagrado e/ou Religioso & Lima (2015) \\
\hline
\end{tabular}

$\mathrm{Na}$ tabela foram identificados os serviços relacionados às interações físicas $\mathrm{e}$ experimentais, onde foi destacado apenas o uso experimental de plantas, animais e terrestres/marinhas em diferentes contextos ambientais. Já nas interações intelectuais e de representação foram identificados serviços de classificação científica, educacional, de herança cultural, entretenimento e sagrado e religioso.

No que se trata sobre os serviços culturais que o manguezal da Ilha do Maranhão presta para a sociedade, estes estão minimamente concentrados nas interações intelectuais e de representação, as quais pode-se dar destaque às classes científico - como já mencionado -, educacional, herança cultural e entretenimento. Esses documentos estão disponíveis em forma de sites, blogs, artigos, teses, dissertações e monografias.

O mangue da Ilha presta um serviço relacionado à utilização da madeira para confecção de instrumentos musicais, fato que está interligado com a classe de "uso experimental de plantas, animais e terrestres/marinhas em diferentes contextos ambientais". Sendo assim, segundo Ferretti (2009) três tambores da ilha e do interior do Maranhão formam o conjunto conhecido como parelha, confeccionados com madeira de mangue, sororó, pau d'arco, angelim ou faveira.

Na classe dos serviços educacionais destaca-se o Projeto "CERMANGUE", o qual a prof. Dra. Flávia Mochel, do Departamento de Oceanografia e Limnologia da Universidade Federal do Maranhão, é coordenadora. O projeto tem como objetivo implementar um centro de excelência em pesquisas, ações de educação ambiental para a recuperação de manguezais em áreas degradadas da zona costeira (Centro de Recuperação de Manguezais - UFMA, 2015).

$\mathrm{Na}$ classe de herança cultural, destaca-se algumas obras literárias de Zenilton de Jesus Gayoso Miranda e José Francisco das Chagas, os quais fazem menção aos mangues e manguezais da Ilha do Maranhão. A partir da apreciação de ambos por este ambiente, foi possível conceber poesias que dão destaque à elementos contidos no manguezal, tais como caranguejo, lamaçais, maré, mangue, palafita, periferia, onde foi possível destacar uma poesia de cada autor. 
Além das poesias, destaca-se também, dentro da Herança Cultural, toponímias presentes na Ilha do Maranhão que tiveram sua origem baseada em características do manguezal. Como por exemplo o bairro Turu, o qual, segundo Matos (2014) Turu/turú é vocábulo de origem Tupi que Bordoni (s/d, p. 690) descreve como espécie de molusco do Pará e "também com molusco bivalente da família dos Terenídeos, e aspecto verminoso”, os quais são são típicos de mangue.

A mesma definição é compartilhada por Cunha (1989 apud Matos, 2014) que acrescenta ainda a descrição feita em 1833 por A.C. Silva, na obra Corografia Paraense, em que este último afirma que turú "he uma especie de cabello aquatico, corpo oblongo e branco, e flagella as embarcações, sendo necessario crenal-as de tempos em tempos, cria-se dentros dos mangues, e sua carne he saborosa".

A partir da origem desse topônimo criado, há em São Luís muitos locais que leva esse nome, além do próprio bairro, tais como Turu, Residencial Primavera Turu, Conjunto Habitacional Turu, Vivendas do Turu, Planalto Turu II, e Ipem Turu. No entanto, segundo Matos (2014) não foi encontrado os mesmos moluscos nessas áreas. Tal fato não exclui a possibilidade desses bairros terem esse nome devido à essa mesma espécie de molusco.

Já no que se refere ao entretenimento, pode-se destacar o turismo na Raposa, onde é visitado a área costeira do município, Esse município é considerado um ponto turístico da Ilha do Maranhão pois possui em seu território praias, dunas e manguezais exuberantes com características cênicas e dignas de visitação. Outro serviço prestado pelo manguezal da Ilha do Maranhão, referese a uma crença religiosa deixada através das estórias dos mais antigos, onde os mesmos contam que seria necessário que os ribeirinhos pedissem proteção para não se perderem no manguezal (LIMA, 2015).

\section{CONSIDERAÇÕES FINAIS}

Ainda são incipientes os trabalhos que abordam as temáticas de serviços ecossistêmicos na Ilha do Maranhão. Porém muitas pesquisas já fazem menção as funções destes ecossistemas e consequentemente aos serviços que podem ser prestados, mesmo sem fazer uso da denominação Serviços Ecossistêmicos.

No que diz respeito aos manguezais da Ilha do Maranhão, as pesquisas encontram-se mais voltadas para os impactos que estas áreas vêm sofrendo do que para a identificação e compreensão da complexidade dos seus serviços e processos. Porém as pesquisas já existentes deram suporte para a identificação e organização dos serviços prestados pelo ecossistema manguezal da área, mesmo sem está fazendo uso do termo serviços ecossistêmicos. 
Os serviços de provisão na Ilha apresentam-se em diversos artigos, citados de forma indireta, seja pela identificação das espécies características deste ambiente, indicando os recursos provenientes do manguezal mais consumidos pela população ou abordando aspectos socioeconômicos das comunidades. Porém, alguns dos artigos da pesquisadora Flávia Mochel, tratam disto como bens e serviços ambientais (e não ecossistêmicos).

No que diz respeito, ao serviços de regulação identificados para a área, é possível considerar que os manguezais prestam serviços de forma direta e indireta para o bem estar humano, visto que na Ilha do Maranhão, estes serviços envolvem desde a manutenção de habitats e berçários ecológicos, que estão diretamente ligados também aos serviços de provisão, posto que garantem a alimentação e sustento de muitas comunidades, até serviços que envolvem o controle de fluxos do ar e de massa, e varáveis físico-químicas.

A identificação dos serviços culturais prestados pelo manguezal da Ilha do Maranhão, só foi possível através da busca de materiais nas diversas áreas do conhecimento: literatura, música, história, geografia e biologia. É possível afirmar que são inexistes trabalhos no contexto da Ilha que abordem especificamente os SE culturais do manguezal.

A partir do que foi exposto, pode-se perceber que o manguezal da Ilha é um ambiente que possui uma diversidade de significados e valores, este sendo tratado aqui como a percepção, crenças e interatividades dos vários atores que utilizam este ecossistema de forma direta ou indireta.

Estudos posteriores que estejam dispostos a identificar novas contribuições relacionadas a regulação etapas e processos do ecossistema manguezal e detalhar ainda mais as que aqui já forem identificadas são de fundamental importância, visto que os serviços de regulação estão intimamente ligados aos processos biológicos, físico-químicos do ambiente. Assim como possuem ligação direta com geodiversidade da área, visto que os recursos abióticos se mostram diretamente relacionados como suporte para prestação destes serviços.

\section{REFERÊNCIAS}

AZEVEDO, A.C.G. de. e CUTRIM, M.V.J. Diatomáceas epífitas em bostrychia Montagne (rhodophyta) do Manguezal da ilha de são luís, Estado do Maranhão, Brasil: Naviculales e bacillarialies. Boletim do Laboratório de Hidrobiologia. Vol. 12. UFMA: 1999. Disponível em: http://www.periodicoseletronicos.ufma.br/index.php/blabohidro/article/view/2018. Acesso: $19 / 10 / 2016$ 
BARBIER, E. B.; HACKER, S. D.; KENNEDY, C.; KOCH, E. W.; STIER, A. C.; SILLIMAN, B. R. The value of estuarine and coastal ecosystem services. Ecological Monographs. Vol. 81. n 2 2011. p 169-193.

BEZERRA, D. da S. O ecossistema manguezal em meio urbano no contexto de políticas públicas de uso e ocupação do solo na bacia do rio Anil, São Luis, Maranhão. Dissertação de Mestrado apresentada ao Programa de Pós-Graduação em Saúde e Ambiente da Universidade Federal do Maranhão: São Luís. 2008. 122 p.

BEZERRA, D. da S. Modelagem do padrão de resistência do Manguezal a elevação do nível do mar. Tese de Doutorado apresentado ao Programa de Pós-Graduação em Ciência do Sistema Terrestre do Instituto Nacional de Pesquisas Espaciais. INPE: São José dos Campos. 2014. 121p.

BRASIL. IICA - Instituto Interamericano de Cooperação para a Agricultura. Desenvolvimento da Pesca e da Aqüicultura no Estado do Maranhão. Publicações, 2003. Disponível em: http://www.iica.org.br/docs/publicacoes/publicacoesiica/desenvpescaaquic-ma.pdf. Acesso em: 14.10.2016

CARVALHO NETA, R.N.F. e CASTRO, A.C.L. de. Diversidade das assembleias de peixes estuarinos da Ilha dos Caranguejos, Maranhão. Arquivos das Ciências do Mar. Vol. 41. Fortaleza, 2008. $48 \quad 4 \quad$ a $\quad 57 \quad$ pg. $\quad$ Disponível em: http://xa.yimg.com/kq/groups/19967785/1370098620/name/07_Artigo_da_Raimunda_Nonata.pdf. Acesso: 16/10/2016.

COMMON INTERNATIONAL CLASSIFICATION OF ECOSYSTEM SERVICES (CICES). Paper prepared for discussion at the expert meeting on ecosystem accounts organized by the UNSD, the EEA and the World Bank, London, 2011. Disponível em: <http://unstats.un.org/unsd/envaccounting/seeaLES/egm/Issue8a.pdf>. Acesso em: 16.10. 2016.

CORREIA, M.M.F. e BRANDÃO, M.D.S. Flora Ficológica Marinha da Ilha de São Luís (Estado do Maranhão, Brasil.). I - CHLOROPHYTA. Arquivo de Ciências do Mar. Vol 14. Fortaleza: 1974. 67-80 p. Acesso: http://www.repositorio.ufc.br/handle/riufc/1590. Acesso: 14/10/2016.

COSTANZA, R.; D'ARGE, R.; DE GROOT, R., FARBER, S.; GRASSO, M.; HANNON, B.; LIMBURG, K.; NAEEM, S.; O'NEILL, R. V.; PARUELO, J.; RASKIN, R. G.; SUT-TON, P.; VAN DEN CORREIA, M. The value of the world's ecosystem services and natural capital. Nature, v. 387, p. 253-260, 1997.

CRUZ, L.D.; MARTINÉZ, C. e FERNANDES, F. R. Comunidades de morcegos em hábitats de uma Mata Amazônica remanescente na Ilha de São Luís, Maranhão. Revista Acta Amazônica. Vol. 37. Manaus: 2007. Disponível em: <https://acta.inpa.gov.br/> . Acesso: 16/10/2016.

CUTRIM, M.V.J. et al. Diatomoflórula de sedimento de manguezal da Ilha de São LuísMaranhão. Anais do III Congresso Brasileiro de Oceanografia. Fortaleza (CE), 20 a 24 de maio de 
2008.

em: https://www.researchgate.net/publication/261473869_Diatomoflorula_de_sedimento_de_mangueza 1_da_ilha_de_sao_luis-maranhao. Acesso: 14/10/2016.

DE GROOT, R.; WILSON, M. A.; BOUMANS, R. M.J. A typology for the classification, description and valuation of ecosystem functions, goods and services. Ecological Economics, v. 41, p. 393-408, 2002.

FERRETTI. Sérgio. Ao som dos tambores. Revista de História. Disponível em: http://www.revistadehistoria.com.br/secao/artigos/ao-som-dos-tambores. Acesso em: 18.10.16

HAINES-YOUNG, R. H.; POTSCHIN, M. B. Proposal for a common international classification of ecosystem goods and services (CICES) for integrated environmental and economic accounting. European Environment Agency. 2010. Disponível em: http://unstats.un.org/unsd/envaccounting/seeaLES/egm/Issue8a.pdf. Acesso em: 18.10.2016

IBGE. Instituto Brasileiro de Geografia e Estática. Cidades. 2010. Disponível em: http://www.cidades.ibge.gov.br/xtras/uf.php?lang=\&coduf=21\&search=maranhao.

Acesso: 29/10/2015.

IMESC. Instituto Maranhense de Estudos Socioeconômicos e Cartográficos. Situação Ambiental da Ilha do Maranhão. São Luís: IMESC, 2011. 57p. Disponível em: http://imesc.ma.gov.br/src/upload/publicacoes/579d2d5480334a4bafbd95d68fcaceaf.pdf. Acesso em: 18.10.2016

JUNK, W. J. et al. Brazilian wetlands: their definition, delineation, and classification for research, sustainable management, and protection. Aquatic Conservation: Marine and Freshwater Ecosystems. Vol. 24. 2014. p. 5-22.

LIMA, Tânia. Os Mangues em Raul Bopp. Revista de Letras. Vol. 1. N 34. Universidade Federal do Ceará, Fortaleza. 2015. p. 78-88.

MATOS, H. R. C. ANÁllSE TOPONÍMICA DE 81 NOMES DE BAIRROS DE SÃO LUÍS/MA. Tese de doutorado apresentada ao Programa de Pós Graduação em Linguística da Universidade Federal do Ceará: Fortaleza. 2014. 347p.

MARTINS, A.L.P. Avaliação da qualidade ambiental da Bacia Hidrográfica do Bacanga (São Luís - Ma) com base me variáveis físico-químicas, biológicas e populacionais: subsídios para um manejo sustentável. Dissertação apresentada ao Programa de Pós Graduação em Sustentabilidade de Ecossistemas da Universidade Federal do Maranhão: São Luís.2008. Disponível em:

https://sigaa.ufma.br/sigaa/verProducao?idProducao=122086\&key=34bbabd55896188d1dcd6a3e67 c13ca6. Acesso: 16/10/2016. 
MACEDO, L. A. A. de. e ROCHA, A.A. Estudo do sistema lagoa-mangue para controle da poluição causada por esgotos no estuário da Ilha de São Luís - MA. Revista DAE. Vol. 44. São Paulo: 1984. Disponível em: http://revistadae.com.br/site/artigo/1193-Estudo-de-sistema-lagoamangue-para-controle-da-poluicao-causada-por-esgotos-nos-estuarios-da-Ilha-de-Sao-Luis---MA. Acesso em: 19/10/2016.

MEDEIROS, T.C.C. A Degradação do Manguezal do Igarapé do Jaracati, no estuário do rio Anil, São Luís - MA: um estudo de caso. Vol. 2. Revista Interface. Tocantins: 2005. 166 a 173 pg. Disponível em: http://revista.uft.edu.br/index.php/interface/article/download/341/238. Acesso em: 16/10/2016.

MOCHEL, F. R. Mangrove Ecosystems in São Luís Island, Maranhão, Brazil. In: KJERFVE, B.; LACERDA, L. D. de L.; DIOP, E. H. S. Mangrove ecosystem studies in Latin America and Africa.Paris, UNESCO. 1997.

MOCHEL, F.R. et al. Degradação dos Manguezais na Ilha de São Luís (MA): processos naturais e impactos antrópicos. In: PROST, M.T.R.C E MENDES, A. Ecossistemas Costeiros: Impactos e Gestão Ambiental. Belém: Museu Paraense Emílio Goeldi, 2001.

MOCHEL, F.R. Manguezais amazônicos: status para a conservação e a sustentabilidade na zona costeira maranhense. In: Martins, M.B. \& Oliveira, T.G. (Org.). Amazônia maranhense: diversidade e conservação. Belém: Editora do Museu Paraense Emílio Goeldi. 2011.

MONTELES et al. Percepção sócio-ambiental das marisqueiras no município de raposa-ma. Revista Brasileira de Engenharia de Pesca. Vol 4. N 2. São Luís. 2009.

MORAES, T. S.; GONÇALVES, E. S.; PASSOS, D. A. dos; OLIVEIRA, I. P.; GONÇALVES, M. F. P. Programa de recuperação em ecossistema de manguezal: o caso do povoado Rio dos Cachorros, São Luís, Maranhão, Brasil. 62 ${ }^{\mathrm{a}}$ Reunião Anual da Sociedade Brasileira para o Desenvolvimento da Ciência, Natal - Rio Grande do Norte. 2010.

MOREIRA, J.F.; BRITO, I. da S. e FARIAS FILHO, M. S. Ocupação desordenada sobre os manguezais da Ilha do Maranhão. In: FARIAS FILHO, M.S. e CELERI, M.J. (Org.) Geografia da Ilha do Maranhão. São Luís: EDUFMA, 2015. 290 p.

MOUCHEREK FILHO, V. E.; VAZ, M. do S. O.; MARANHÃO, S. C. Avaliação organoléptica e análise bromatológica, para fins nutricionais do camarão, caranguejo e sururu (in natura) consumidos na Ilha de São Luís - MA. Cadernos de Pesquisa da Universidade Federal do Maranhão. Vol. 14. N. 1. p. 24-34. 2003.

NOGUEIRA, N. M. C. e FERREIRA-CORREIA, M. M. Cyanophyceae/cyanobacteria in red mangrove forest at mosquitos and coqueiros estuaries, São Luís, state of Maranhão, Brazil. Brazilian Journal Biology. Vol. 61. N.3, São Carlos.. 2001. 10 p. Disponível em: 
http://www.scielo.br/scielo.php?script=sci_arttext\&pid=S1519-69842001000300002.

Acesso: $16 / 10 / 2016$.

NOVAES, R.C. et al. Análise da Sensibilidade Ambiental da parte ocidental da Ilha do Maranhão. Anais XIII Simpósio Brasileiro de Sensoriamento Remoto, Florianópolis, Brasil, 21-26 abril 2007, INPE, p. 4089-4096. Disponível em: http://marte.sid.inpe.br/col/dpi.inpe.br/sbsr@80/2006/11.15.22.54/doc/4089-4096.pdf. $\quad$ Acesso: $14 / 10 / 2016$.

NUNES, M. de L. F. Distribuição e fracionamento do fósforo nos sedimentos dos rios Bacanga e Anil na Ilha do Maranhão. Dissertação apresentada ao Programa de Pós-Graduação em Química da Universidade Federal do Maranhão: São Luís. 2013. 97 pg.

OLIVEIRA, V. M. de. e MOCHEL, F. R. Macroendofauna bêntica de substratos móveis de um manguezal sob impactos das atividades humanas no sudoeste da Ilha de São Luís, Maranhão, Brasil. Boletim Laboratório de Hidrobiologia. Vol. 12. São Luís: UFMA. 75-93 p. Disponível em: https://www.researchgate.net/publication/278018947. Acesso: 17/10/2016.

PAIXÃO, V.M. et al. Ocorrência e abundância de caranguejos chama-marés do gênero Uca (crustacea, ocypodidae) no manguezal do araçagy, Ilha São Luís, Maranhão. Anais do VIII Congresso de Ecologia do Brasil, 23 a 28 de Setembro de 2007, Caxambu - MG. 2 pg. Disponível em: http://www.seb-ecologia.org.br/viiiceb/pdf/803.pdf. Acesso em: 19/10/2016.

SILVA, J. de R.R. e ALMEIDA, Z, da S. de. Zoneamento Vertical dos crustáceos bentônicos em substratos inconsolidados do manguezal do quebra-pote na Ilha de São Luís, Maranhão, Brasil. Boletim Técnico-Científico CEPENE. Vol. 10. ICMBIO. São Luís: 2002. 65 a 83 pg. Disponível em: http://www.icmbio.gov.br/cepene/images/stories/publicacoes/btc/vol10/Art05_Vol101.pdf. Acesso em: 14/10/2016.

SCHAEFFER-NOVELLI, Y.; CINTRÔN-MOLERO, G.; ADAIME, R. R.; CAMARGO, T. M. Variability of mangrove ecosystems along the Brazilian coast. Estuaries, v. 13, n. 02, p. 204-218, 1990

SCOTT, D.A.; JONES, T. A. Classification and inventory of wetlands: a global overview. Vegetatio, v. 118, n. 3, p.16, 1995

SILVA, G.S. da. Et al. Distribution and Fractionation of Metals in Mangrove Sediment from the Tibiri River Estuary on Maranhão Island. Revista Virtual de Química. Vol 6. Niterói - RJ: 2014. Disponível em: http://rvq.sbq.org.br/index.php/rvq/about/contact. Acesso: 14/10/2016.

SOUZA, L. P.; SOUZA, A. I.; ALVES, F. LILLEBØ, A. I. Ecosystem services provided by a complex coastal region: challenges of classification and mapping. Scientific Reports, v. 6, n. $22782,2016$. 
SOUZA, U.D.V.; FEITOSA, A.C. Ocupação e uso da zona costeira do Estado do Maranhão. In: Encontro de Geógrafos da América Latina (EGAL), 2009, Montevidéu. Anais do XII Encontro de Geografos da América Latina. 2009. p. 2415-2430. Disponível em: 〈http://www.egal2009.com/〉. Acesso em: 02/11/2016.

\section{AGRADECIMENTOS}

Agradecemos a Coordenação de Aperfeiçoamento de Pessoal do Nível Superior pela concessão da bolsa de mestrado através do Programa de Pós-graduação em Geografia da Universidade Federal do Rio Grande do Norte.

Recebido em: 15/08/2018

Aceite para publicação em: 05/11/2018 